BMJ Open

Sport \&

Exercise

Medicine

\title{
Force and acceleration characteristics of military foot drill: implications for injury risk in recruits
}

\author{
Patrick P J Carden, ${ }^{1,2}$ Rachel M Izard, ${ }^{3}$ Julie P Greeves, ${ }^{3}$ Jason P Lake, ${ }^{1}$ \\ Stephen D Myers ${ }^{1}$
}

To cite: Carden PPJ Izard RM, Greeves JP, et al. Force and acceleration characteristics of military foot drill: implications for injury risk in recruits. BMJ Open Sport Exerc Med 2015;0: e000025. doi:10.1136/ bmjsem-2015-000025

- Prepublication history for this paper is available online To view these files please visit the journal online (http://dx.doi.org/10.1136/ bmjsem-2015-000025).

Accepted 2 August 2015

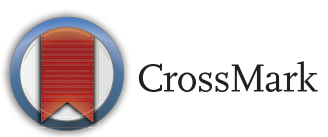

${ }^{1}$ Department of Sport \& Exercise Sciences, University of Chichester, Chichester, UK ${ }^{2}$ School of Sport and Health Sciences, University of Exeter, Exeter, UK ${ }^{3}$ Department of Occupational Medicine, Headquarters Army Recruiting and Training Division, Upavon, UK

Correspondence to Dr Stephen D Myers; S.Myers@chi.ac.uk

\section{ABSTRACT}

Background: Foot drill involving marching and drill manoeuvres is conducted regularly during basic military recruit training. Characterising the biomechanical loading of foot drill will improve our understanding of the contributory factors to lower limb overuse injuries in recruits.

Aim: Quantify and compare forces, loading rates and accelerations of British Army foot drill, within and between trained and untrained personnel.

Methods: 24 trained soldiers (12 men and 12 women; TRAINED) and 12 civilian men (UNTRAINED) performed marching and five drill manoeuvres on force platforms; motion capture recorded tibial position. Peak vertical impact force (PF), peak vertical loading rate (PLR), expressed as multiples of body weight (BW) and peak tibial impact acceleration (PTA) were recorded.

Results: Drill manoeuvre PF, PLR and PTA were similar, but higher in TRAINED men (PF, PLR: $p<0.01$; PTA: $p<0.05)$. Peak values in TRAINED men were shown for the halt (mean (SD); PF: 6.5 (1.5) BW; PLR: 983 (333) BW/s PTA; PTA: 207 (57) $\mathrm{m} / \mathrm{s}^{2}$ ) and left turn (PF: 6.6 (1.7) BW; PLR: 928 (300) BW/s; $184(62) \mathrm{m} / \mathrm{s}^{2}$ ). Marching PF, PLR, PTA were similar between groups and lower than all drill manoeuvres (PF: 1.1-1.3 BW; PLR: $42-70 \mathrm{BW} / \mathrm{s} ; \mathrm{p}<0.01 ;$ PTA: $23-38 \mathrm{~m} / \mathrm{s}^{2} ; p<0.05$ ).

Conclusions: Army foot drill generates higher forces, loading rates and accelerations than activities such as running and load carriage, while marching is comparable to moderate running $(10.8 \mathrm{~km} / \mathrm{h})$. The large biomechanical loading of foot drill may contribute to the high rate of overuse injuries during initial military training, and strategies to regulate/reduce this loading should be explored.

\section{INTRODUCTION}

The objective of initial military training is to transform a civilian into a trained soldier. In the UK, up to 10000 men and women (à 8\%) enter British Army initial (phase 1) training annually ${ }^{1}$ compared with over 69000 in the US Army. ${ }^{2}$ During initial training, male and female recruits sustain a high number of lower limb overuse injuries. ${ }^{3-7}$

\section{Summary box}

- First study to quantify the forces, loading rates and accelerations associated with military foot drill (drill manoeuvres and marching) in male and female soldiers, and untrained men.

- Drill manoeuvre forces, loading rates and accelerations exceed those for running and load carriage, while marching generates similar values to running $(10.8 \mathrm{~km} / \mathrm{h})$.

- The high forces, loading rates and accelerations associated with foot drill are likely to be key contributory factors to overuse injuries such as stress fractures.

Stress fractures are a typical lower limb overuse injury, with an occurrence rate in male and female British Army recruits of up to 83 and 53 per 1000 , respectively, with $50 \%$ of confirmed cases occurring to the tibia/ fibula (Greeves JP and Izard RM. Headquarters Army Recruiting and Training Division (ARTD). Unpublished dataset cited with permission, 2014).

Foot drill is a fundamental activity of the military and is practised regularly during initial military training. ${ }^{8}$ Foot drill involves marching with an exaggerated heel strike, and regimented manoeuvres performed while marching and standing in place (at the halt) characterised by an exaggerated stamping of one foot into the ground from $90^{\circ}$ hip flexion. Timetabled drill sessions for British Army recruits range from 4 to over $13 \mathrm{~h}$ per week. Additional drill is undertaken daily when moving and carrying out duties around camp, ${ }^{9}$ and the additional non-timetabled transits are reported to exceed 18 miles each week for some regiments. ${ }^{9}$ Previous research has explored biomechanical loading during activities commonly undertaken by military recruits such as running ${ }^{10}{ }^{11}$ and load carriage, ${ }^{12}$ but not drill which may make a substantial contribution to overall loading. 
Stress fracture aetiology is multifactorial, but repeated exposure to high levels of bone strain and strain rate play a key role in the development of bone microdamage. ${ }^{13}$ Consequently, the combination of repetitive loading cycles combined with inadequate bone remodelling is a recognised cause of lower limb stress fracture. ${ }^{14} 15$ Peak impact force and loading rate are a non-invasive measure of lower limb bone loading used to quantify the potential for developing overuse injuries such as metatarsal and tibial stress fractures. ${ }^{10} 16-18$ Tibial impact acceleration is also an important predictor of injury risk. ${ }^{19}$

Lower limb injury rates, in particular stress fractures, are reportedly higher for running in women compared with men, ${ }^{16} 20$ and also in female recruits. ${ }^{18}{ }^{21-23}$ However, to date, no study has compared loading patterns of marching and drill manoeuvres between sexes in military populations. The pattern of loading may be an important contributory factor to lower limb overuse injuries in women who typically have a lower lean muscle mass and cross-sectional area (CSA) of the bone than men. ${ }^{16} 24$

Injury rates in recruits are highest in the early weeks of initial training. ${ }^{25}$ It is, therefore, possible that the biomechanical responses to foot drill and propensity to injury may differ in untrained personnel than those who have completed military training and have reached necessary levels of physical robustness. It is, therefore, important to measure and compare the force and acceleration characteristics of foot drill performed by untrained and trained personnel.

The aim of this study was to quantify impact forces, loading rates and tibial acceleration of Army foot drill in male and female recruits and to compare values between trained and untrained men.

\section{METHODS}

\section{Participants}

Twenty-four trained soldiers (12 men and 12 women; TRAINED) and 12 male students attending a
Uniformed Public Services course (UNTRAINED) volunteered to participate in the study (table 1). Participants were medically fit and free from any known lower limb injury and gave their written informed consent. The UK Ministry of Defence Research Ethics Committee (protocol number: 401/GEN/13) and the University of Chichester Research Ethics Committee (protocol number: 1112_31) granted approval for the study.

\section{Protocol}

Participants attended one $3 \mathrm{~h}$ testing session and completed, in triplicate, a march and five foot drill manoeuvres on force platforms in the order listed in table 2. Participants wore new in-service Combat Assault Boots, insoles and socks, with their own shorts and t-shirts. Retroreflective markers were attached to the skin overlying the tibial tuberosity of both legs. Participants were asked not to perform any prolonged, weight-bearing, arduous exercise in the $24 \mathrm{~h}$ preceding their visit.

\section{Instrumentation}

Marching and drill manoeuvres were performed on two embedded (side-by-side) force platforms (Kistler 9581, Kistler Instruments, Hook, UK) sampling at $1000 \mathrm{~Hz}$. Force platform data were used to calculate peak vertical impact force and peak vertical loading rates. Retroreflective marker position data were captured at $250 \mathrm{~Hz}$ (Vicon Nexus 10-camera motion analysis system, Vicon Motion Systems, Oxford, UK) and used to calculate peak tibial impact acceleration. Motion and force data were synchronised using a Vicon MX control unit.

\section{Biomechanical analyses}

Vertical ground reaction force data were filtered using a fourth-order Butterworth filter; a cut-off frequency of $100 \mathrm{~Hz}$ was applied following power spectrum analysis to ensure over $95 \%$ of signal content was retained. The onset of each drill manoeuvre was defined as the point where the increase in vertical ground reaction force was

Table 1 Participant characteristics

\begin{tabular}{|c|c|c|c|}
\hline & \multicolumn{3}{|l|}{ Group } \\
\hline & Trained women ${ }^{\star}$ & Trained ment & Untrained menł \\
\hline Age (years) & $23(5)$ & $23(4)$ & $18(1) \S$ \\
\hline Height $(\mathrm{cm})$ & 169 (3)ף & $180(8)$ & $180(5)$ \\
\hline Body weight** (kg) & $66.6(7.7)$ & 81.5 (11.2)†† & 70.6 (13.3) \\
\hline BMI $\left(\mathrm{kg} / \mathrm{m}^{2}\right)$ & $23.3(2.6)$ & $25.3(3.4)$ & 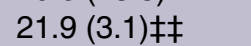 \\
\hline \multicolumn{4}{|c|}{ 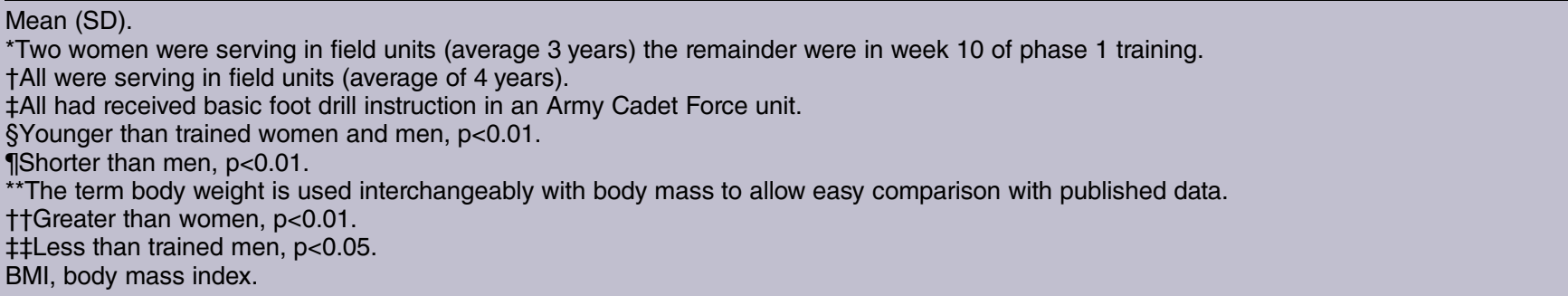 } \\
\hline
\end{tabular}


Table 2 Drill manoeuvres completed in addition to marching

\begin{tabular}{|c|c|c|c|}
\hline Manoeuvre & $\begin{array}{l}\text { At the } \\
\text { halt }\end{array}$ & Marching & $\begin{array}{l}\text { Stamping } \\
\text { leg }\end{array}$ \\
\hline Halt & & $\sqrt{ }$ & $\mathrm{R}$ \\
\hline Left turn & $\sqrt{ }$ & & $\mathrm{R}$ \\
\hline Right turn & $\sqrt{ }$ & & $\mathrm{L}$ \\
\hline Come-to-attention & $\sqrt{ }$ & & $\mathrm{L}$ \\
\hline Stand-at-ease & $\sqrt{ }$ & & $\mathrm{L}$ \\
\hline
\end{tabular}

$15 \mathrm{~N}$ greater than the participant's body weight (BW). The peak vertical impact force was identified as the highest instantaneous vertical ground reaction force value. Vertical loading rate was calculated as the first derivative of vertical ground reaction and time using finite difference method of differentiation, with peak vertical loading rate defined as the largest instantaneous loading rate.

A residual analysis of tibial tuberosity marker coordinate data for the stamping leg (table 2) was undertaken to establish the appropriate cut-off frequency $(12 \mathrm{~Hz})$ to apply using a fourth-order Butterworth filter. Vertical tibial acceleration was then derived from the displacement of the tibial tuberosity. The peak tibial impact acceleration was defined as the highest positive vertical acceleration during the stance phase of manoeuvres performed while marching and during impact for manoeuvres performed at the halt.

\section{Statistical analysis}

Force data were averaged over the three trials (stamping leg for the drill manoeuvres), then normalised to BW, and are reported as multiples of BW or BW/s. Data were analysed using a two-way analysis of variance to determine the effect of foot drill experience by different groups (TRAINED women, TRAINED men,
UNTRAINED men), marching and drill manoeuvre on the dependent variables of peak vertical impact force, peak vertical loading rate and peak tibial impact acceleration. Differences were located using Bonferroni t tests. Statistical analysis was performed using Statistical Package for Social Sciences (V.20, SPSS Inc, Chicago, Illinois, USA). Data are reported as mean (SD) and $95 \%$ confidence limits. An $\alpha$ level of $\mathrm{p}<0.05$ was used to determine statistical significance.

\section{RESULTS}

\section{Peak vertical impact force}

Peak forces (table 3) were higher within groups for all drill manoeuvres compared with marching $(p<0.01)$. Between groups, TRAINED men had higher peak vertical impact force values than TRAINED women and UNTRAINED men for all manoeuvres $(p<0.01)$ except marching, which were similar across groups.

\section{Peak vertical loading rate}

Peak vertical loading rates (table 4) were higher within groups for all drill manoeuvres compared with marching $(\mathrm{p}<0.01)$. Between groups, TRAINED men had higher peak vertical loading rate values than TRAINED women and UNTRAINED men for all manoeuvres $(p<0.01)$ except marching, which were similar across groups.

\section{Peak tibial impact acceleration}

Peak tibial impact acceleration (table 5) was higher within groups for all drill manoeuvres compared with the marching $(p<0.05)$. Between groups TRAINED men had higher peak tibial impact acceleration values than TRAINED women and UNTRAINED men for all manoeuvres $(p<0.05)$ except marching, which were similar across groups.

\section{DISCUSSION}

We demonstrated high vertical peak forces, loading rates and tibial acceleration generated with drill manoeuvres, irrespective of sex and experience. These indices of

Table 3 Normalised peak vertical impact force (multiples of body weight) generated by the groups while marching and during drill manoeuvres

\begin{tabular}{|c|c|c|c|c|c|c|}
\hline & March & Halt & To attention & To ease & Right turn & Left turn \\
\hline \multicolumn{7}{|l|}{ Trained women } \\
\hline Mean (SD) & $1.1(0.1)$ & $4.1(1.3)^{\star} \dagger$ & $3.4(0.8)^{*} \dagger$ & $3.1(0.8)^{\star} \dagger$ & $3.5(0.9)^{*} \dagger$ & $3.5(0.9)^{\star} \dagger$ \\
\hline Lower/upper CL & $1.1 / 1.2$ & $3.3 / 4.9$ & $2.9 / 3.9$ & $2.6 / 3.5$ & $2.9 / 4.1$ & $2.9 / 4.1$ \\
\hline \multicolumn{7}{|l|}{ Trained men } \\
\hline Mean (SD) & $1.2(0.1)$ & $6.5(1.5)^{*}$ & $6.1(1.2)^{*}$ & $6.2(1.5)^{*}$ & $5.9(1.6)^{*}$ & $6.6(1.7)^{\star}$ \\
\hline Lower/upper CL & $1.2 / 1.3$ & $5.5 / 7.4$ & $5.3 / 6.8$ & $5.2 / 7.1$ & $4.9 / 6.9$ & $5.5 / 7.7$ \\
\hline \multicolumn{7}{|l|}{ Untrained men } \\
\hline Mean (SD) & $1.3(0.2)$ & $4.4(1.1)^{\star} \dagger$ & $4.3(1.1)^{*} \dagger$ & $3.7(0.7)^{\star} \dagger$ & $4.2(0.9)^{\star} \dagger$ & $4.6(1.1)^{\star} \dagger$ \\
\hline Lower/upper CL & $1.2 / 1.3$ & $3.8 / 5.1$ & $3.6 / 4.9$ & $3.3 / 4.1$ & $3.7 / 4.8$ & $3.8 / 5.3$ \\
\hline
\end{tabular}


Table 4 Normalised peak vertical loading rates (BW/s) generated by the different groups while marching and during drill manoeuvres

\begin{tabular}{|c|c|c|c|c|c|c|}
\hline & March & Halt & To attention & To ease & Right turn & Left turn \\
\hline \multicolumn{7}{|l|}{ Trained women } \\
\hline Mean (SD) & $42(14)$ & $461(254)^{\star} \dagger$ & $343(98)^{*} \dagger$ & 316 (99)† & $343(117)^{\star} \dagger$ & $324(123)^{\star} \dagger$ \\
\hline Lower/upper CL & $33 / 50$ & $300 / 623$ & $281 / 405$ & $253 / 378$ & $269 / 417$ & $246 / 401$ \\
\hline \multicolumn{7}{|l|}{ Trained men } \\
\hline Mean (SD) & 64 (31) & $983(333)^{*}$ & $832(201)^{\star}$ & $924(309)^{\star}$ & $794(266)^{\star}$ & $928(300)^{\star}$ \\
\hline Lower/upper CL & $45 / 84$ & $771 / 1194$ & $704 / 959$ & $728 / 1120$ & $624 / 963$ & $737 / 1118$ \\
\hline \multicolumn{7}{|l|}{ Untrained men } \\
\hline Mean (SD) & $70(27)$ & $491(169)^{\star} \dagger$ & $499(118)^{\star} \dagger$ & $420(60)^{*} \dagger$ & $515(138)^{*} \dagger$ & $536(179)^{\star} \dagger$ \\
\hline Lower/upper CL & $53 / 87$ & $383 / 598$ & $424 / 574$ & $382 / 459$ & $427 / 602$ & $422 / 650$ \\
\hline
\end{tabular}

${ }^{*}$ Greater than march.

†Lower than trained men; both $p<0.01$.

BW, body weight; CL, 95\% confidence limits.

injury risk were markedly higher than those for marching, which, in turn, were comparable with activities such as running.

\section{Peak vertical impact force}

The peak vertical impact forces for Army foot drill in this study were higher than the mean values reported previously in untrained university students wearing training shoes. ${ }^{26}$ It is likely that training shoes attenuated peak vertical impact force compared with the Combat Assault Boot; ${ }^{27}$ also, the peak vertical impact forces do not truly reflect those experienced during foot drill, which is normally only performed in boots. However, the authors ${ }^{26}$ do discuss one individual recording a peak vertical impact force of 6 and 6.5 BW for the stand-at-ease and halt, respectively, which support the values reported by the current study.

Two common elements of military training syllabi and sources of mechanical loading are running and load carriage. British Army initial training recruits are required to complete a 1.5 mile run wearing training shoes, in times ranging from 10:00 to 14:00 min (equivalent speeds $4.0-3.0 \mathrm{~m} / \mathrm{s}$ ). Peak impact forces reported for men running at similar speeds $(3-5 \mathrm{~m} / \mathrm{s})$ range from 1.6 to $2.3 \mathrm{BW} .^{11} 2829$ In comparison, the peak vertical impact forces reported for the drill manoeuvres (table 3) far exceed those values for running (range 3.1-6.6 BW), while marching forces are similar (1-1.3 BW) to those reported ${ }^{1129}$ for running at 3 and $3.5 \mathrm{~m} / \mathrm{s}$ (1.6 and $1.3 \mathrm{BW}$, respectively). Wang et $a l^{12}$ measured peak vertical impact force in men carrying a $32 \mathrm{~kg}$ backpack at $1.67 \mathrm{~m} / \mathrm{s}$ and reported values of $1.92 \mathrm{BW}$, around half those measured for the drill manoeuvres, but similar to those recorded for marching. Another source of loading is jumping or dropping from height, typically occurring when recruits complete obstacle/ assault courses. Mean drill manoeuvre peak vertical impact forces for TRAINED men (6.3 BW), women (3.5 BW) and UNTRAINED men (4.2 BW) were $41 \%, 3 \%$ and $13 \%$ greater than those reported by Decker $e t a l^{30}$ for a $60 \mathrm{~cm}$ drop landing $(3.4 \mathrm{BW})$.

\section{Peak vertical loading rates}

The peak vertical loading rate for the drill manoeuvres ranged from 316 to $983 \mathrm{BW} / \mathrm{s}$ (table 4), whereas the highest loading rate measured by Munro et $a l^{11}$ for running $(113 \mathrm{BW} / \mathrm{s}$ at $5 \mathrm{~m} / \mathrm{s})$ was only around a third of our lowest recorded value. The peak vertical loading

Table 5 Peak impact tibial acceleration $\left(\mathrm{m} / \mathrm{s}^{2}\right)$ generated by the groups while marching and during drill manoeuvres

\begin{tabular}{|c|c|c|c|c|c|c|}
\hline & March & Halt & To attention & To ease & Right turn & Left turn \\
\hline \multicolumn{7}{|l|}{ Trained women } \\
\hline Mean (SD) & $23(6)$ & $114(47)^{\star} \dagger$ & $94(28)^{\star} \dagger$ & $79(24)^{\star} \dagger$ & $96(33)^{\star} \dagger$ & $90(34)^{*} \dagger$ \\
\hline Lower/upper CL & $19 / 26$ & $87 / 140$ & $78 / 110$ & $65 / 92$ & $77 / 115$ & $71 / 109$ \\
\hline \multicolumn{7}{|l|}{ Trained men } \\
\hline Mean (SD) & $34(14)$ & $207.2(57)^{\star}$ & $178(45)^{\star}$ & $183(54)^{*}$ & $169(46)^{*}$ & $184(62)^{\star}$ \\
\hline Lower/upper CL & $26 / 42$ & $175 / 239$ & $153 / 203$ & $153 / 213$ & $143 / 195$ & $149 / 219$ \\
\hline \multicolumn{7}{|l|}{ Untrained men } \\
\hline Mean (SD) & $38(16)$ & $121(33)^{\star} \dagger$ & $111(27)^{\star} \dagger$ & $91(21)^{\star} \dagger$ & $107(21)^{\star} \dagger$ & $113(30)^{\star} \dagger$ \\
\hline Lower/upper CL & $29 / 47$ & $102 / 140$ & $96 / 126$ & $78 / 103$ & $95 / 118$ & $96 / 129$ \\
\hline
\end{tabular}

*Greater than march.

tLower than trained men; both $p<0.05$.

CL, 95\% confidence limits. 
rates for marching $(42-70 \mathrm{BW} / \mathrm{s})$ are similar to those reported for running at $3 \mathrm{~m} / \mathrm{s}(77 \mathrm{BW} / \mathrm{s})$ by Munro et al. ${ }^{11}$ Given the reported 18 miles of transiting between lessons for the first 2 weeks of initial training, ${ }^{9}$ the peak vertical loading rate represents a significant biomechanical load. The peak vertical loading rate values $(35 \mathrm{BW} / \mathrm{s}$ ) reported for load carriage by Wang $e t a l^{12}$ were also lower than those measured for all the drill manoeuvres, but similar for those recorded during marching $(42-70 \mathrm{BW} / \mathrm{s})$.

\section{Peak tibial impact acceleration}

Peak tibial impact acceleration is often used as an indirect measure of loading experienced by the tibia after a portion of the impact has been attenuated by footwear. ${ }^{28} 31$ Therefore, measurement of tibial impact acceleration provided an approximation of impact loading of the tibia during foot drill. All groups experienced significantly larger peak tibial impact acceleration for drill manoeuvres compared with marching (table 5). Similarly to peak tibial impact acceleration and peak vertical loading rate, no significant differences were observed between drill manoeuvres. Given that the common feature between the drill manoeuvres is stamping, this explains the larger peak tibial impact acceleration and similarities in peak vertical impact force and peak vertical loading rate.

Marching and drill manoeuvres exhibited greater peak tibial impact acceleration $\left(23-207 \mathrm{~m} / \mathrm{s}^{2}\right)$ than running at moderate speeds (women: speed $3.7 \mathrm{~m} / \mathrm{s}$, peak tibial impact acceleration $6 \mathrm{~m} / \mathrm{s}^{2} ;$ men: speed $3.5 \mathrm{~m} / \mathrm{s}$, peak tibial impact acceleration $\left.11 \mathrm{~m} / \mathrm{s}^{2}\right) .28$ Furthermore, the largest peak tibial impact acceleration observed (halt: $207 \mathrm{~m} / \mathrm{s}^{2}$ ) was higher than that reported for a $30 \mathrm{~cm}$ drop jump $\left(155 \mathrm{~m} / \mathrm{s}^{2}\right)$ and only $14 \%$ lower than that for a $50 \mathrm{~cm}$ drop jump $\left(242 \mathrm{~m} / \mathrm{s}^{2}\right) .{ }^{31}$

The large forces, loading rates and accelerations are a result of the unique requirements of foot drill compared with other activities. Soldiers performing drill manoeuvres are instructed to flex the hip to around $90^{\circ}$, and then stamp the heel in to the ground as hard as possible in an attempt to make a 'loud noise ${ }^{32}$ We suggest that the large peak vertical impact force and associated peak vertical loading rates during drill manoeuvres were due to the effective mass of the stamping limb travelling at a higher velocity prior to ground contact when compared with marching and running. This is supported by the higher peak tibial impact acceleration recorded during drill manoeuvres when compared with marching. Further comparison of peak tibial impact acceleration between foot drill and other high-impact exercise such as running and landing from height is necessary to validate these conclusions in a comparable population.

The high biomechanical loading of drill manoeuvres is further illustrated by comparing the peak vertical impact forces and peak vertical loading rates with values reported for drop/depth jumps, an activity often used in studies to generate high loading forces through the lower limbs. While the peak vertical impact force of the drill manoeuvres were of a similar magnitude, the peak vertical loading rates were 2.6-6.1, and 2-2.9 times greater for men and women, respectively, when compared with a $60 \mathrm{~cm}$ drop-jump landing. ${ }^{30}$ Given the disparity in peak vertical loading rates between drop jumps and foot drill and the importance of peak vertical loading rate as an indicator of tibial stress fracture risk, ${ }^{28}$ the commonly performed manoeuvres selected by this study have a greater potential for chronic injury than an activity used specifically to generate high loading rates.

A possible explanation for the large disparity in loading rates between foot drill and other high-impact activities is that for the latter, individuals will attempt to actively reduce the impact and increase the duration of loading by greater knee and hip flexion, ${ }^{33-35}$ whereas during drill they will not. The experimenters observed that all participants impacted the ground with a straight leg, which might also explain the high loading rates. While a comprehensive analysis of lower limb joint kinematics during foot drill manoeuvres is necessary to confirm this, the peak tibial impact accelerations were significantly higher during all drill manoeuvres compared with marching. This suggests that individuals had insufficient time to consciously reduce the mechanical loading through knee and hip flexion.

\section{Influence of sex and experience}

TRAINED men displayed significantly greater peak vertical impact forces, peak vertical loading rates and peak tibial impact accelerations for all manoeuvres with the exception of marching when compared with TRAINED women and UNTRAINED men (tables 3-5). The higher values in TRAINED men may be partly due to differences in mean BW, which was typically $13-18 \%$ higher than the other two groups (table 1). Although lean muscle mass was not measured, all participants were fit, highly active, lean young adults, so it is reasonable to believe that the TRAINED men also had a greater lean muscle mass. This higher BW and assumed muscle mass would enable the TRAINED men to impart more force into the ground (ie, stamp harder) when performing foot drill. Furthermore, the TRAINED men were experienced soldiers who had served for an average of over 4 years, and as a result were likely more technically proficient in performing foot drill.

Despite the greater biomechanical loading of TRAINED men, the volume of foot drill performed by serving soldiers is markedly lower than recruits unless they are undertaking ceremonial duties. As a result, the biomechanical loading experienced by serving soldiers during foot drill may be offset by longer periods of recovery, thereby reducing their risk of overuse injury. Despite the greater values recorded in TRAINED men for foot drill, TRAINED women and UNTRAINED men also demonstrated large peak vertical loading rates and peak tibial impact accelerations, similar to, or higher than, values reported for running and drop-jump landings. ${ }^{11}{ }^{28-31}$ It is also important to note that even though the peak vertical impact force and peak vertical loading 
rate were corrected for BW, women have lower bone $\mathrm{CSA}^{16}$ and smaller muscle mass to attenuate force, therefore, the relative forces transmitted are likely to be higher.

Previous research has suggested that loading rate and tibial acceleration during impact play a larger role in the development of lower limb stress fracture compared with the magnitude of impact force. ${ }^{15}{ }^{28}$ It is thought that the neuromuscular system is unable to actively attenuate a load applied at a high rate resulting in cartilage, ligament, tendon and bone absorbing the impact. ${ }^{28}{ }^{31}$ If the mechanical load applied to bone is of sufficient magnitude, microdamage will occur. ${ }^{13-15} 36$

This is relevant when considering the high occurrence of stress fractures sustained by British Army and other military recruits during initial training. Recruits, unless they are on field exercises, will perform many hours of foot drill during formerly timetabled sessions and while transiting around camp during their initial training. The present study has illustrated that this amount of foot drill will place the lower limbs under a large magnitude of biomechanical loading. The high number of hours of foot drill is reflected in the pattern and nature of injuries reported in initial training. ${ }^{25}$ If there is adequate rest between loading cycles, bone will sufficiently remodel. ${ }^{15}$

However, when considering the high frequency of lower limb loading that recruits experience due to foot drill (timetabled and additional), physical training sessions (timetabled and additional) and long loaded marches, the rate of bone microdamage may often exceed the rate of remodelling resulting in stress fracture. ${ }^{15}$ Muscle mass also plays an important role in attenuating forces, which is supported by association of smaller calf girth and increased stress fracture risk. ${ }^{24} 37$ Women and untrained men will have a lower muscle mass and/or strength and therefore will be at greater risk even though their impact forces are lower than trained men.

In our study, all participants were well rested when performing foot drill manoeuvres. The forces and accelerations may not be fully representative of those generated during foot drill during initial training where recruits are fatigued from the cumulative effects of their training. Previous research has reported a reduced ability to actively attenuate impact when running, landing from heights and carrying load in a fatigued state. $^{12} 2931$ Given the risk of underestimating the forces and accelerations during drill, the current measurements should be repeated with participants in a fatigued state to fully quantify the biomechanical loading experienced by recruits. We were also unable to recruit an untrained female group and this is another area that needs to be addressed in future studies giving the growing role of women in the Armed Forces.

\section{Summary}

Indices of injury risk were higher for all foot drill manoeuvres than other recognised high loading activities such as running, load carriage and drop jumping for TRAINED men and women and UNTRAINED men. While the forces and accelerations for marching were lower compared with the drill manoeuvres, they were still comparable to running, demonstrating that both represent a substantial mechanical load placed on the lower limbs of the recruit. However, before any recommendations can be made to reduce the mechanical loading of foot drill, it is important to determine the total amount performed by recruits during initial training. This would enable training organisations to establish if there is currently adequate rest between loading cycles of running, foot drill and other physical activities or if shock attenuation characteristics of footwear need consideration.

Acknowledgements The authors acknowledge the support received from the Army Training Regiment Winchester, 47 Regiment, Royal Artillery, 12 Regiment, Royal Artillery, and Chichester College. They would also like to thank Dr Kath Shorter, School of Science and Technology at the University of New England, Armidale, New South Wales, Australia, for her assistance with the data collection for the untrained men.

Contributors The study was conceived and designed by all authors. Data collection and analysis was carried out by SDM, PPJC and JPL. All authors contributed to the writing of the manuscript.

Competing interests None declared.

Patient consent Obtained.

Ethics approval The UK Ministry of Defence Research Ethics Committee; University of Chichester Research Ethics Committee.

Provenance and peer review Not commissioned; internally peer reviewed.

Open Access This is an Open Access article distributed in accordance with the Creative Commons Attribution Non Commercial (CC BY-NC 4.0) license, which permits others to distribute, remix, adapt, build upon this work noncommercially, and license their derivative works on different terms, provided the original work is properly cited and the use is non-commercial. See: http:// creativecommons.org/licenses/by-nc/4.0/

\section{REFERENCES}

1. UK Ministry of Defence. UK Armed Forces Quarterly Personnel Report. London: Defence Statistics (Tri Service), 2014.

2. Kapp L. Recruiting and retention: an overview of FY2012 and FY2013 results for active and reserve component enlisted personnel. Washington, USA: Congressional Research Service, 2014.

3. Friedl K, Nuovo J, Patience T, et al. Factors associated with stress fracture in young army women: indications for further research. Mil Med 1992;157:334-8.

4. Ross RA, Allsopp A. Stress fractures in Royal Marines recruits. Mil Med 2002;167:560-5.

5. Armstrong DW III, Rue JP, Wilckens JH, et al. Stress fracture injury in young military men and women. Bone 2004;35:806-16.

6. Rauh MJ, Macera CA, Trone DW, et al. Epidemiology of stress fracture and lower-extremity overuse injury in female recruits. Med Sci Sports Exerc 2006;38:1571-7.

7. Wood AM, Hales R, Keenan A, et al. Incidence and time to return to training for stress fractures during military basic training. J Sports Med 2014. (accessed 23 Jan 2015).

8. Wardle MK A defence of close-order drill: a reply to "modern infantry discipline". J R United Serv Inst 1934;79:714-22.

9. Wilkinson DM, Rayson MP, Bilzon JL. A physical demands analysis of the 24-week British Army Parachute Regiment recruit training syllabus. Ergonomics 2008;51:649-62.

10. Creaby MW, Dixon SJ. External frontal plane loads may be associated with tibial stress fracture. Med Sci Sports Exerc 2008;40:1669-74

11. Munro CF, Miller DI, Fuglevand AJ. Ground reaction forces in running: a reexamination. J Biomech 1987;20:147-55. 
12. Wang $\mathrm{H}$, Frame J, Ozimek $\mathrm{E}$, et al. Influence of fatigue and load carriage on mechanical loading during walking. Mil Med 2012;177:152-6.

13. Schaffler MB, Radin EL, Burr DB. Mechanical and morphological effects of strain rate on fatigue of compact bone. Bone 1989;10:207-14.

14. Warden SJ, Burr DB, Brukner PD. Stress fractures: pathophysiology, epidemiology, and risk factors. Curr Osteoporos Rep 2006;4: 103-9.

15. Zadpoor AA, Nikooyan AA. The relationship between lower-extremity stress fracture and the ground reaction force: a systemic review. Clin Biomech 2011;26:23-8.

16. Bennel KL, Malcolm SA, Thomas SA, et al. Risk factors for stress fractures in track and field athletes. A twelve-month prospective study. Am J Sports Med 1996;25:810-18.

17. Queen RM, Abbey AN, Chuckpaiwong B, et al. Plantar loading comparisons between women with a history of second metatarsal stress fractures and normal controls. Am J Sports Med 2009;37:390-5

18. Hamstra-Wright $\mathrm{K}$, Bliven $\mathrm{K}$, Bay $\mathrm{C}$. Risk factors for medial tibial stress syndrome in physically active individuals such as runners and military personnel: a systematic review and meta-analysis. $\mathrm{Br} J$ Sports Med 2015;49:362-9.

19. Shorten M, Winslow DS. Spectral analysis of impact shock during running. Int J Sport Biomech 1992;8:288-304.

20. Murphy DF, Connolly DA, Beynnon BD. Risk factors for lower extremity injury: a review of the literature. Br J Sports Med 2003;37:13-29.

21. Burne SG, Khan KM, Boudville PB, et al. Risk factors associated with exertional medial tibial pain: a 12 month prospective clinical study. Br J Sports Med 2004;38:441-5.

22. Gemmell I. Injuries among female army recruits: a conflict of legislation. JRSM 2002;95:23-7.

23. Bijur P, Horodyski M, Egerton W, et al. Comparison of injury rates during cadet basic training by gender. Arch Pediatr Adolesc Med 1997; 151:456-61.

24. Beck TJ, Ruff CB, Mourtada FA, et al. Dual-energy X-ray absorptiometry derived structural geometry for stress fracture prediction in male U.S. Marine Corps recruits. J Bone Miner Res 1996;11:645-53.
25. Sharma J, Greeves J, Byers M, et al. Musculoskeletal injuries in British Army recruits: a prospective study of diagnosis-specific incidence and rehabilitation times. BMC Musculoskeletal Disord 2015;16:106.

26. Connaboy C, Lyall N, Simpson RJ, et al. Ground reaction forces in military drill: Implications for injury and training. British Association of Sports and Exercise Medicine (BASEM) Annual Conference. London, UK, 2010.

27. Rawcliffe A, Psycharakis S, Graham SM, et al. Effects of three different types of standard issue British Army footwear on vertical ground reaction force in marching drills. International Congress of Soldiers' Physical Performance. Boston, USA, 2014.

28. Milner CE, Ferber R, Pollard CD, et al. Biomechanical factors associated with tibial stress fracture in female runners. Med Sci Sports Exerc 2006;38:323-8.

29. Mizrahi J, Verbitsky O, Isakov E, et al. Effect of fatigue on leg kinematics and impact acceleration in long distance running. Hum Mov Sci 2000;19:139-51.

30. Decker MJ, Torry MR, Wyland DJ, et al. Gender differences in lower extremity kinematics, kinetics, and energy absorption during landing. Clin Biomech (Bristol, Avon) 2003;18:662-9.

31. Moran KA, Marshall BM. Effect of fatigue on tibial impact accelerations and knee kinematics in drop jumps. Med Sci Sports Exerc 2006;38:1836-42.

32. UK Ministry of Defence. The Drill Manual. Prepared under the direction of the Chief of the General Staff Army Code No. 70166 (D/DAT/13/28/97), London, UK: Ministry of Defence, 1990.

33. McMahon T, Valiant G, Frederick E. Groucho running. J Appl Physiol 1987;62:2326-37.

34. McNitt-Gray JL, Yokoi T, Millward C. Landing strategy adjustments made by female gymnasts in response to drop height and mat composition. J Appl Biomech 1993;9:173-90.

35. Puddle DL, Maulder PS. Ground reaction forces and loading rates associated with parkour and traditional drop landing techniques. J Sports Sci Med 2013;12:122-9.

36. Milgrom C, Finestone A, Levi $\mathrm{Y}$, et al. Do high impact exercises produce higher tibial strains than running? $\mathrm{Br} J$ Sports $\mathrm{Med}$ 2000;34:195-9.

37. Bennell K, Crossley K, Jayarajan J, et al. Ground reaction forces and bone parameters in females with tibial stress fracture. Med Sci Sports Exerc 2004;36:397-404. 